\title{
Transition to retirement for expatriates in the UAE: a psychological perspective
}

Book or Report Section

Accepted Version

Rowson, T. S. (2015) Transition to retirement for expatriates in the UAE: a psychological perspective. In: Al-Karam, C. Y. and Haque, A. (eds.) Mental Health and Psychological Practice in the United Arab Emirates. Palgrave Macmillan, pp. 93-102. ISBN 9781137567529 doi:

https://doi.org/10.1057/9781137558237 Available at http://centaur.reading.ac.uk/91277/

It is advisable to refer to the publisher's version if you intend to cite from the work. See Guidance on citing.

To link to this article DOI: http://dx.doi.org/10.1057/9781137558237

Publisher: Palgrave Macmillan

All outputs in CentAUR are protected by Intellectual Property Rights law, including copyright law. Copyright and IPR is retained by the creators or other copyright holders. Terms and conditions for use of this material are defined in the End User Agreement. 


\section{www.reading.ac.uk/centaur}

\section{CentAUR}

Central Archive at the University of Reading

Reading's research outputs online 
Book: Psychology in the UAE

Chapter title: transition to retirement for expatriates: A psychological perspective.

Author: Dr. Tatiana Schifferle Rowson

\section{Introduction}

As people are tending to live for longer, the study of ageing has become a growing area of research. Among the themes that have been highlighted in the international literature, the topic of retirement is gaining prominence due to the increasing number of years individuals are expected to live in retirement. This extension of retirement, as a stage of life, means that understanding the ageing and adjustment processes and what older people are actually looking for, is important to promote emotional and psychological wellbeing for those living longer. Many studies have been conducted on the psychological aspects involved in the adjustment to retirement and old age. Some studies have covered the issues of globalization and even migration in retirement but few publications specifically explore the issue of repatriation as part of the transition to retirement.

In the United Arab Emirates (U.A.E.), where a substantial percentage of executives and professionals are expatriates, the issue of retirement and adjustment to the home (or new) country is critical for those approaching their retirement age. Nevertheless, this topic is rarely discussed and many individuals embark on their retirement journey ill-prepared to face the adjustment process of retirement, especially with all the changes that moving to a different country, whether called home or not.

It must be highlighted that the current literature on the psychology of ageing and retirement is wide and also includes studies on coping with more challenging circumstances, such as ill health, caring responsibilities, bereavement, financial challenges, etc; these circumstances make the adjustment process of ageing even tougher on the individual. For the purpose of this chapter, the expatriate population is assumed to be in general good health with reasonable financial 
stability at the time of retirement. Furthermore, this chapter explores the transition to retirement for professionals and executives. There are various groups of expatriates and exceptions to the conditions the author assumes. However, it is not possible in one chapter to explore in depth all the many challenges associated with ageing and retirement. Therefore, this chapter aims to explore the theories of retirement and old age adjustment from the perspective of professionals and executives expatriates only, discussing the challenges and opportunities they may face on re-adjusting. Additionally, this chapter will discuss strategies individuals and organizations can implement in order to allow an easier transition to retirement.

\section{Earlier Theories of Successful Ageing}

Theories of successful ageing and exploring the role of the older person in society gained popularity following World War II, particularly in the United States of America, the United Kingdom and a few other European countries. The expansion and consolidation of retirement, as a legitimate stage of a worker's life, also dates from the same period. Different countries adopted retirement practices (and policies) consistently with their level of development and the need to use retirement to address other social issues, such as a strategy to create employment opportunities for younger workers. In this post war period (1950s and 1960s), the views on adjustment to old age and the role of older people were informed by the functionalist paradigm. Two contrasting theoretical models were developed: one accepting and justifying their withdrawal from mainstream social roles and the other focused on maintaining older people active within society. These two theories are: Disengagement theory and Activity theory.

Disengagement theory, developed by Cumming and Henry (1961), argued that as people age, they naturally withdraw (or disengage) from the various roles in their lives, slowly decreasing their interaction with others. In their perspective, disengagement was a desirable outcome for the individual and for the society, 
and was triggered by the proximity of death. They warned about the importance of this mutual desire for disengagement between the older person and society, arguing that a mismatch in expectation, or as they called it 'unilateral disengagement', would lead to a reduced life satisfaction and compromised psychological wellbeing.

Disengagement theory was heavily criticized, due to its questionable evidence and over-generalized ideas. Although this is not considered a valid theory today, its influence can be clearly noted in the retirement policies of most countries, indicating that there is an expectation that the ageing process involves a certain level of disengagement.

Derived from the role theory, Activity theory (Havighurst, 1968) maintained that individuals are influenced by their social roles and relationship with others. Therefore life satisfaction in old age depends on the active maintenance of social relationships and meaningful activities. The Activity theory emphasized the quantity, not necessarily the quality of activities, and argued that the void from activities such as work or childcare should be filled by alternative ones, such as leisure or volunteering. The activity theory gained strength as the Disengagement theory was criticized. However, like the Disengagement theory, this theory also failed to take in consideration personal differences and circumstances that may be an impediment to the engagement in activities. The emphasis on the quantity of activities was also a point criticized in this theory, as it emerged that only activities that are psychologically relevant seem to impact life satisfaction.

These theories were particularly influential to research on ageing, and even though they cannot be generalized as they were presented, some concepts can be useful to understand retirement. Both theories emphasize discontinuity as a consequence of ageing, whether this discontinuity leads to engagement in other activities (as suggested by the Activity theory) or not (as suggested by the Disengagement theory). One may say that ageing and retirement will inevitably involve discontinuities. For expatriate retirees discontinuity is an evident aspect. 
Over the transition to retirement, they have no choice but to accept their discontinuities and replace certain activities by others. It is fair to say that the experiences of change (or discontinuity) are a natural aspect of ageing and retirement. The process of adjustment to the various disengagements is not necessarily natural and desirable as Cumming and Henry (1961) argued, in the same way that engaging in equally fulfilling activities is not as simple as described by Activity theory. The transition to retirement is a complex process for individuals, where a number of factors come together either contributing or hindering adjustment to the new status.

\section{Life Course Perspective \& The Retirement of Expatriates}

Further to the previous theories, other ways to think about old age and retirement later emerged. There was a stronger emphasis on the experience of continuity throughout adulthood and old age. Generally speaking, these new theories took a life course approach to understand the process people go through as they adjust to old age and retirement transitions. Life course approaches are based on the premise that old age is a part of adulthood and not a separate stage as the previous theories had argued.

Continuity theory (Atchley, 1989; 1999) follows the life course approach and emphasizes that the outcomes of ageing and retirement are a consequence of the experiences in adulthood and more specifically in midlife. This theory assumes that in midlife, individuals experience a stable life, with a consistent pattern. This consistent existence provides individuals with the elements to build their identities and lifestyle. Atchley (1989) argues that a common adaptive strategy to adjust to changes related to old age is the experience of continuity in lifestyle. Continuity means that these general life patterns - i.e. activities, ideas, place of living, personal values - remain consistent throughout later life by being absolutely unchanged or by presenting only minor fluctuations; a break in a pattern would characterize discontinuity. Atchley's Continuity theory makes a 
distinction between internal continuities - i.e. ideas, feelings, values, etc - and external continuities - i.e. place of residence, activities, etc. It is emphasized that continuity is experienced in the psychological, behavioral and sociological level, integrating all aspects of one's life.

The Continuity theory was criticized but never discredited. On the contrary, more theories having their premises based on the idea of continuity emerged in the various domains of research on ageing. These theories took a life course perspective to understand how life unfolds as people age. Life course perspectives assume that various events and experiences throughout lives of individuals influence their old age. Thus, later life outcomes are perceived as a consequence of adulthood. Most theories based on the life course approach introduce an element of 'continuation', not necessarily presented in the same way that the Continuity theory does.

The main criticism of the Continuity theory is related to how the idea of continuity itself was argued. It has been highlighted that various forces and life-events may disrupt individuals' trajectories, and therefore lead to a break in patterns. This is particularly relevant, as people increasingly experience changes during midlife, such as changes in employment status, family reconfiguration and general health. Atchley (1989) argues that Continuity theory is not an assumed sameness throughout life, but a consistence and coherence in patterns where, on balance, continuities are more frequently experienced than discontinuities. Interestingly, he adds that the study of continuity can only take place in retrospect, and the degree to which individuals experience continuity is determined by their own assessment of how their present situation compares to past circumstances. The standards individuals use to evaluate the experience or not of continuity are not necessarily obvious to an external observer, as they derive from the personal constructs of individuals themselves (Kelly, 1955). Our personal constructs or mental framework are shaped by our own life experiences. At the same time, they play a role in influencing our future experiences, informing our choices and enabling consistent coping strategies to 
change to be used throughout life.

The degree of the changes people experience and the knowledge of such changes are also factors influencing their adjustment to possible discontinuities. Atchley (1999) argues that age-related changes tend to be gradual, allowing the adaptation process to be planned and put into action. He continues saying that in these cases it is easier to maintain continuity and there is a reduced chance of a life crisis. One of the keys to adjustment when continuity is not possible lies in preparing oneself for retirement. Planning and preparation is an effective strategy to create the necessary transitional bridges and therefore prevent an identity crisis. It can be said that when it comes to retirement, expatriate retirees know in advance that they would be leaving the company, and most likely the country, at some specific point in time. This allows time for planning the transition from work to retirement (and from one country to another country), however the effectiveness of the plan is inevitably challenged by the logistics of its implementation.

Compared to non-expatriate retirees, that may have more options when it comes to maintaining continuity, expatriates are likely to experience additional discontinuities as they retire. Usually, for expatriates living in the U.A.E. who are dependent on a work visa to stay in the country, these additional discontinuities tend to be linked to the fact that after retirement they have to move out of the country - therefore leaving behind the community to which they belonged (obviously, there are exceptions). In addition to place of residence other common discontinuities experienced by expatriate retirees are linked to lifestyle, social activities, friends, professional identity, and other aspects associated with being an expatriate.

It might seem that the repatriation process is not going to be an issue for many expatriate executives and professionals, especially in the Middle East. These expatriates and their families tend to keep close ties to their home country, and are aware that the assignment will eventually come to an end, as well as their 
residency rights. However, as counterintuitive as it may seem, going back 'home' requires a considerate amount of effort. The literature, on the repatriation of executives and their families, indicates that individuals returning home usually expect that they would be able to easily reconnect with the community, resume friendships, generate new network of contacts/support and easily fit into their previous lifestyle. This expectation however is unlikely to materialize, leading to a reverse culture shock (Hurn, 1999). On returning to the home country, expatriates tend to find that not only has the environment changed and people have moved on, but they would also have changed as a result of being exposed to a different cultural context. The experience of living in a different location, particularly a different country and culture, impacts on individuals' personal constructs, altering their mental frameworks and self-concept. These internal changes sometime can only be noticed once the individual returns home and faces what Atchley would call 'internal discontinuities'.

The literature on ageing and adult development points out that the same way that a sense of self (and identity) evolves as a result of their experiences (Kelly, 1955; Giddens, 1991), individuals can also develop additional facets to their identities. For this current generation of retirees, non-economic related activities and interests became an important source of social integration - ultimately shaping identity beyond traditional routes such as work and family. This malleable nature of individuals' sense of self is an important resource to draw upon when balancing continuities and discontinuities related to retirement and ageing. For expatriate retirees, this may be one of the most effective strategies to a smooth transition to retirement. In the next section, other psychological coping strategies to ageing will be explored.

\section{The Psychology of Coping and Adjustment to Ageing}

Life transitions, as a consequence of ageing, can only be assessed as being negative or positive in relation to an individual's personal goals, preferences and 
self-definitions. As people age, at the psychological level, they can adapt to challenging and difficult situations while still maintaining some internal continuity. Collins and Smyer (2005) argue that people might find it necessary to discontinue, or disengage from certain life domains or personal goals where they may not be able to perform in order to maintain a sense of self-worth. Theorists of psychological adjustment to ageing state that successful ageing, when personal circumstances change, is dependent on the individuals' ability to either adjust their environment so their goals are met, or select their goals or domains based on their best abilities (Brandtstädter and Greve, 1994; Brandtstädter and Rothermund, 1994; Baltes and Baltes, 1990; Baltes et al., 1998; Freund and Baltes, 1998).

As people age, they tend to focus on activities and personal goals that are more rewarding and that can be performed without much effort. This strategy is called optimisation, and helps preserve the individuals' sense of self. So, in terms of making choices related to maintaining continuity, on a psychological level, these are the criteria influencing choices. It must be said that some individuals may make wrong choices in terms of activity domains or goals to pursue which may lead to reduced self-esteem and emotional wellbeing.

Furthermore, whenever individuals are faced with difficulties in sustaining selected goals, life domains and activities, compensatory processes take over in order to maintain a sense of self. Some authors suggest that as a way to compensate, one might adjust the environment so goals can continue to be achieved (for instance: use reading glasses to continue enjoying reading the newspaper; move to 'senior' league in sport to be able to continue practicing at a slower pace); or if this is not possible or sufficient to maintain life goals, one might adjust the goals and expectations downwards (for instance: developing a taste for radio or TV news programs if eye problems cannot be compensated for or taking a role such as refereeing or coaching if unable to continue to practise a sport). 
It is interesting to note that older adults use different strategies to successfully adapt and preserve their emotional wellbeing, even when they are faced with changes that are challenging and unwelcomed. Also, it has been highlighted in the literature, that more important than having the innate ability to adapt, individuals can, and should, take a pro-active role in managing their own adjustment to retirement and ageing limitations. For expatriates retiring, these same coping strategies can be used to adjust their goals and activity domains in the face of relocation. Some aspects of peoples' lives, with some adjustments and compromises can be sustained; other aspects can be substituted by something similar or downplayed. In both cases, it is important to have an open mind and to be proactive to finding bridges and new paths for life in retirement.

\section{Applying theoretical concepts to real life for a smoother transition}

The purpose of this chapter is to discuss theories of ageing and the transition to retirement from the perspective of expatriates. It is important to highlight that expatriate retirees do not only face the practical and emotional task of relocating following retirement, but as much as anyone growing older, they may experience the changes in circumstances and losses commonly associated with ageing. These further challenges such as health decline or caring responsibilities, as well as the financial aspect of retiring, may hinder even further the sense of wellbeing for retired expatriates, as they increase the possible discontinuities and hinder the possibility of further engagement in old or new activities. However, in order to broaden the discussions to include such aspects of life, more than one chapter would be necessary. So, the aim of this chapter is to explore the challenges expatriate retirees, of executive and professional backgrounds, face when having to leave the U.A.E. and return to their home country (or other country); with some practical strategies individuals may use to facilitate a smooth transition to retirement. In this section the key points will be summarized and a few examples from individuals who retired from the U.A.E. are presented for illustration 
purposes, their names have been changed to maintain their anonymity.

From the literature, it is clear that a successful transition to retirement is dependent on an optimum balance between continuities and discontinuities and in the ability of individuals to realistically manage the way desirable continuities can be experienced. A positive attitude and flexibility to change are important traits to have for a successful transition to retirement, as these aspects allow internal continuities to make up for external discontinuities and vice versa. In addition to this, the psychology of adjustment to retirement emphasizes that to be pro-active is key to allowing individuals to take control of their transitions using a combination of an action plan (external processes) and open mindset (internal processes).

Although people tend to neglect retirement planning beyond the financial side, it is important to start early and have a vision of what is the ideal outcome. Having a goal or a vision allow individuals to devise a better plan. The first step is to review current life domains, goals and activities. The idea is to be critical about the variety of possibilities for continuities individuals have. For instance, for people that are solely work-focused, this may be the moment to reflect on what other life domains, interests or aspects of their identities they would like to develop. These aspects may have been previously neglected due to work and family responsibilities. Ideally, individuals should be engaged in a few of these activities and interests well in advance to retirement. These other interests and activities are helpful to fill the immediate void left from work, as well as to create ways of social integration in the retirees' new place of residency.

For Rose and lan, the idea of leaving Abu Dhabi to go back to their home country caused them some level of anxiety, as they did not have defined plans regarding what they would do with their time. For them, the only comfort was the belief that they would be able to meet new people and make friends through some of their leisure activities. Rose and lan were keen golfers and bridge players, and these activities have always proven to 
be a good way to meet new people.

Clearly, as the literature argues different people will cope with the changes associated with ageing in a variety of ways, depending on their attitude to retirement as well as other factors such as health and financial status. Executives and professional retiring from the UAE often find themselves in a comfortable position to find alternative ways to phase their return home.

Franz and Barbra retiring from Dubai decided that their best alternative was to phase their return home. They decided to keep a holiday apartment in Dubai and spend a few months of the year here and the remaining months in their home country. After 20 years, most of their friends and social life were here, so provided they were in good health and financially this was not a problem, for them, that would be a good alternative to an abrupt change.

In some cases, when there was no time for planning. The simple awareness of discontinuities can help the retiree to be realistic on what to expect from the retirement transition.

Thomas and June were leaving Dubai after 15 years. A few months before their departure they realized that they had never made any plans or arrangements for a smooth transition. Even their hobbies were linked to the desert, very different from the environment of their home country. They decided not to rush to make any decisions, but simply be prepared to adapt to this new 'adventure' ahead of them.

Finally, it cannot be neglected that technology has opened opportunities for continuity, engagement and social interaction with people that share similar interests that may, or may not, be in the same locality. Executives and professionals retiring from the UAE are usually familiar with the different technological platforms to keep in touch with others. These platforms - Internet video calls, forums and social media - allow retirees to create a sense of continuity despite the dramatic discontinuities they may be necessarily 
experiencing (i.e. relocation).

The more executive and professional retirees became aware of the elements to a successful transition to retirement, the better they can plan and control the process. It is important that Human Resource professionals and Organizational/Business Psychologists also understand the transition to retirement to better advise and guide retirees. Some thought and planning, taking in consideration the points described in this chapter, should allow executives and professionals retiring from the U.A.E. to create bridges, real or virtual, to make the transition to retirement, and the move to a 'new' (or home) country less stressful.

\section{References}

Atchley, R. C. (1989). A Continuity Theory of Normal Aging. The Gerontologist, vol. 29, no. 2, pp. 183-190.

Atchley, R. C. (1999). Continuity and Adaptation in Aging: Creating Positive Experiences. The Johns Hopkins University Press.

Baltes, P. B. and Baltes, M. M. (1990). Psychological perspectives on successful aging: the model of selective optimization with compensation. In Baltes, P.B. and Baltes, M. M. (eds) Successful Aging: Perspectives from the Behavioral Sciences. New York: Cambridge University Press. Chapter 1, pp. 1-34.

Baltes, P. B., Lindenberger, U. and Staudinger, U. M. (1998). Life-span theory in developmental psychology. In Damon, W. and Lerner, R. M. (eds) Handbook of Child Psychology. Vol. 1 - Theoretical Models of Human Development. New York: Wiley, pp.1029-1143.

Brandstädter, J. and Greve, W. (1994). The aging self: stabilizing and protective processes. Development Review, v.14, pp.52-80.

Brandstädter, J. and Rothermund, K. (1994). Self-precepts of control in the middle and late adulthood: buffering losses by rescaling goals. Psychology and Aging, v.9, pp. 265-273.

Collins, A.L. and Smyer, M.A. (2005). The resilience of self-esteem in late adulthood. Journal of Aging Health. 2005 Aug;17(4):pp. 471-89. 
Cumming, E. and Henry, W. (1961). Growing Old. New York: Basic.

Freund, A. M. and Baltes, P. B. (1998). Selection, optimization and compensation as strategies of life-management: correlations with subjective indicators of successful aging. Psychology and Aging. v.13, pp. 531-543.

Giddens, A. (1991). Modernity and self-identity self and society in the late modern age. Polity Press, Cambridge.

Havighurst, R.J. (1968). Personality and patterns of aging. The Gerontologist, 8 , pp.20-23.

Hurn, B. J. (1999). Repatriation - the toughest assignment of all. Industrial and Commercial Training, Vol. 31 Iss: 6, pp.224-228

Kelly, G. (1955). The psychology of personal constructs. Vol. I, II. Norton, New York.

World Health Organization, WHO. (2002). Active Aging: A Policy Framework, Geneva. 